injury and reduced NAA. (Kaufmann WE, Wang PY, Koth CW, Denckla MB, Barker PB. Evaluation of brain metabolism in neurofibromatosis type 1 by magnetic resonance spectroscopy. Ann Neurol September 1999;46:528. CNS 28th Annual Meeting Abstract, Oct 13-16, 1999).

COMMENT. This work is an extension of previous reports from Johns Hopkins University concerning the relationship between UBOs and lower IQs in children with neurofibromatosis-1 (Denckla MB et al. Am I Med Genet 1996;67:98102). (see Progress in Pediatric Neurology III, PNB Publ, 1997;pp291-294, for a review of these and other reports, some showing conflicting results).

Ped Neur Briefs Nov 1997;11:84, reviews an article on learning disability subtypes in children with neurofibromatosis; academic underachievers fall into 3 groups: $40 \%$ have normal IQ test results, 50\% have general learning disabilities, and $14 \%$ have visuospatial and motor coordination problems, without language deficits.

\title{
HYPOMELANOSIS OF ITO: A GENETIC MOSAICISM
}

Evidence purporting that the so-called hypomelanosis of Ito (HI) syndrome does not exist as a distinct multisystem birth defect is presented by geneticists and dermatologists at Bad Salzschlirf, and Philipp University of Marburg, Germany. HI is a nonspecific pigmentary disorder representing a cutaneous marker of many different states of genetic mosaicism. The clinical findings are highly variable, not always involving brain, eyes or bones, occurrence is sporadic, and cytogenetic abnormalities involve many different chromosomes, especially the Xchromosome. The terms $\mathrm{HI}$, incontinentia pigmenti achromians, pigmentary dysplasia, and pigmentary mosaicism are synonyms of the same cutaneous signs. "Pigmentary mosaicism of the Ito type" should be substituted for the term "HI syndrome."(Kuster W, Konig A. Hypomelanosis of Ito: No entity, but a cutaneous sign of mosaicism. Am I Med Genet Sept 1999;85:346-350). (Respond: Wolfgang Kuster MD, Clinical Genetics, TOMESA Clinic for Allergy, RiedstraBe 18, D-36361, Bad Salzschlirf, Germany).

COMMENT. HI is a relatively common disorder in pediatric neurology clinics, involving 1 in every 1000 patients attending a service in Spain (PascualCastroviejo I et al. Hypomelanosis of Ito; neurological complications in 34 cases. Can I Neurol Sci 1988;15:124-129). CNS anomalies include mental and motor retardation, microcephaly, hypotonia, hyperkinesia, ataxia, seizures, and deafness. Eye defects include microphthalmia, ptosis, nystagmus, cataracts, and retinal degeneration. Bone anomalies include dental enamel defects, short stature, limb asymmetry, scoliosis, syndactyly, and polydactyly. These multisystem defects are explained, not as a single syndrome, but by different genetic defects and a sign of mosaicism, as evidenced by a variety of reported underlying chromosomal abnormalities.

\section{MOVEMENT DISORDERS}

\section{TOURETTE SYNDROME AND DYSTONIA: GENETICALLY RELATED}

A three-generation family in which 5 members were diagnosed with focal dystonia and 3 with tics, Tourette syndrome, and hyperactivity is reported from the Radcliffe Infirmary, Oxford, and Queen Elizabeth Hospital, Birmingham, England. One with dystonic head tremor subsequently died of a motor neuron disease. The findings of dystonia and Tourette syndrome in 8 members of a single 
family suggest a common "susceptibility gene" and an etiologic relationship for these disorders. (Nemeth AH, Mills KR, Elston JS, Williams A, Dunne E, Hyman NM. Do the same genes predispose to Gilles de la Tourette syndrome and dystonia? Report of a new family and review of the literature. Mov Disord September 1999;14:826-831). (Reprints: Andrea H Nemeth MD, PhD, The Wellcome Trust Centre for Human Genetics, Windmill Road, Headington, Oxford OX3 7BN, UK).

COMMENT. A relationship between some cases of Tourette syndrome and focal dystonia, suggested by previous scattered reports in the literature, is strengthened by this family of 8 affected members, and may indicate a sharing of predisposing genes. TS is frequently familial, and may be inherited as an autosomal dominant trait. Focal dystonias are genetically heterogeneous and can be inherited as autosomal dominant traits with incomplete penetrance. The family described in which TS and dystonia cosegregate may be genetically distinct from other forms of TS and focal dystonia. It is of interest that hyperactivity occurred in one patient, who was "always on the go," and ADHD is a frequent comorbid disorder with TS. Choreiform movements sometimes coexist with ADHD (Prechtl syndrome), but focal dystonia is a rare and subtle finding.

We have recently observed a family in which a 2 year old is diagnosed with idiopathic dyskinesia, including dystonic movements, and a 5 year old has ADHD (Keating G, Millichap JG. Division of Neurology, Children's Memorial Hospital, unpublished observations).

Tizanidine (Zanaflex) therapy in Tourette syndrome and ADHD. When administered alone or in combination with conventional therapies, tizanidine benefited 63 patients (ages 4-19 years), and side effects, especially drowsiness and fatigue, were fewer and less severe than those with clonidine, another centrally acting a2-adrenergic agonist. (Foradada III, JR. Ann Neurol Sept 1999;46:529, abstract).

\section{PERSISTENT SYDENHAM'S CHOREA}

Patients with Sydenham's chorea (SC) seen at the Movement Disorders Clinic of the Federal University of Minas Gerais, Brazil, 1993-1998, were followed prospectively to determine the proportion with persistent symptoms more than 2 years (Group 2, N=16), and clinical features that might differentiate patients with duration less than 2 years (Group 1, N=16). No significant differences were found between Groups 1 and 2 in respect to $\mathrm{M} / \mathrm{F}$ ratio $(50 / 50$ and 31/68, respectively, $\mathrm{p}=0.23)$; age at onset (10.9 and 9.3 years, $\mathrm{p}=0.23)$; \% with arthritis (37 and 19, $\mathrm{p}=0.28)$; carditis \% (31 and 50, $\mathrm{p}=0.28)$; hemichorea $\%(25$ and $6, \mathrm{p}=0.14)$; generalized chorea $\%$ (75 and $94, \mathrm{p}=0.14)$; and severity of chorea (moderate to severe, $p=0.59)$. All patients were taking penicillin to prevent recurrent streptococcal infection and RF. (Cardoso F, Vargas AP, Oliveira LD, Guerra AA, Amaral SV. Persistent Sydenham's chorea. Mov Disord Sept 1999;14:805-807). (Reprints: Francisco Cardoso MD, Dept of Neurology, UFMG, Av Pasteur 89/1107, 30150-290 Belo Horizonte MG, Brazil).

COMMENT. Sydenham's chorea of moderate to severe degree may persist longer than 1 year in $50 \%$ of patients. Female gender and the presence of carditis may be risk factors for a longer duration of SC, although the data are not statistically significant.

These findings are at variance with the generally held belief that SC is self-limiting, usually lasting 2 to 6 months. However, other movement and behavioral disorders may occur as sequelae of SC, including tics, ADHD, and 